\title{
Efeitos alelopáticos sobre a germinação de sementes de soja (Glycine max L.Merrill) ${ }^{1}$
}

\author{
Allelopathic effects on the germination of soybean seeds \\ (Glycine max L.Merrill)
}

\author{
Michele Fernanda Bortolini² Andréa Maria Teixeira Fortes ${ }^{3 *}$
}

\begin{abstract}
Resumo
Este trabalho teve como objetivo estudar o efeito de substâncias naturais encontrados em exsudados radiculares de outras culturas, sobre a geminação da soja. Foram realizados dois experimentos: no primeiro, sementes de trigo (Triticum aestivum), triticale (Triticum sp.), milho (Zea mays), ervilhaca (Vicia sativa), e aveia preta (Avena strigosa), foram colocadas para germinar, em rolos de papel, em BOD a $25^{\circ} \mathrm{C}$. Estas sementes foram descartadas e os papéis reutilizados para germinação de sementes de soja, utilizando como solução-teste exsudados radiculares, e como controle apenas água destilada para umedecer os papéis. Para o segundo experimento, foi utilizado extrato aquoso da parte área de aveia preta (Avena strigosa), como umidificante do papel, onde posteriormente as sementes de soja foram colocadas para germinar, em BOD a $25^{\circ} \mathrm{C}$. Constataram-se efeitos alelopáticos dos exudados radiculares, sobre a porcentagem de germinação das sementes de soja, não sendo verificado efeito sobre o tempo e velocidade média de germinação, mas verificou-se interferência negativa do extrato de aveia preta sobre o tempo e velocidade média de germinação das mesmas.
\end{abstract}

Palavras-chave: Soja, alelopatia, germinação

\begin{abstract}
This work had as objective to study the effect of natural substances found in root exsudates of other crops on the gemination of soybean seeds. Two experiments were accomplished. For the first experiment wheat seeds (Triticum aestivum), cale (Triticum sp.), corn (Zea mays), ervilhaca (Vicia sativa), and black oat (Avena strigosa), that were placed to germinate, in paper rolls, in BOD at $25^{\circ} \mathrm{C}$. These seeds were discarded and the papers were reused for germination of soybean seeds, using as solution-test root exsudates, and as control distilled water to humidify the paper. For the second experiment, aqueous extract of above-ground part of black oat (Avena strigosa) was used to humidify the paper where the soy seeds were placed to germinate, in BOD at $25^{\circ} \mathrm{C}$. Allelopatic effects alelopáticos of the root exsudates were verified on the percentage of germination of the soybean seeds, but it was not verified effect on the time and medium speed of germination. It was observed negative interference of black oat extract on the time and medium speed of soybean seeds germination.
\end{abstract}

Key words: Soybean, allelopathy, germination

1 Trabalho desenvolvido junto ao laboratório de Fisiologia Vegetal do Centro de Ciências Biológicas e da Saúde da Universidade Estadual do Oeste do Paraná- Campus Cascavel

2 Bióloga, mestranda do curso de Agronomia - Produção Vegetal da Universidade Federal do Paraná

3 Professora doutora do curso de Ciências Biológicas da Universidade Estadual do Oeste do Paraná

* Autor para correspondência.

Recebido para publicação 10/09/04 Aprovado em 28/04/05 


\section{Introdução}

A soja, pertencente à família Leguminosae, subfamília Faboideae, originária da China, foi introduzida no Brasil em 1882 na Bahia, depois São Paulo, em Campinas, no ano de 1892, chegando na região sul no Rio Grande do Sul em 1900. O rápido desenvolvimento da cultura deve-se a necessidade do reaproveitamento da infra-estrutura da lavoura de trigo, que ficava ociosa nas estações mais quentes, e a conseqüente necessidade de encontrar uma leguminosa para a sucessão. Atualmente, a soja se tornou uma das principais fontes alimentares dos animais e do homem, pois constitui a maior fonte de óleo vegetal e de proteína, além de ser rica em vitaminas e minerais (COSTA, 1996).

$\mathrm{Na}$ busca de maior produtividade e conservação do solo, além de procedimentos adotados no manejo das culturas, tem-se o controle das plantas daninhas. A interferência das plantas daninhas sobre outras plantas pode se dar pela liberação de uma variedade de metabólicos primários e secundários no ambiente a partir das folhas, raízes e matéria orgânica. A investigação destes compostos sobre as plantas constituise o estudo da alelopatia. Embora o fenômeno seja de difícil comprovação nas interações planta-planta, suas potenciais aplicações na agricultura são interessantes, uma vez que reduções na produção vegetal causadas por plantas daninhas ou resíduos de culturas prévias podem, em alguns casos, ser atribuídas a alelopatia. (TAIZ; ZEIGER, 1998 ).

Os mecanismos de ação dos agentes alelopáticos ainda são pouco conhecidos, dada à dificuldade de se separar os efeitos secundários das causas primárias. No entanto estudos já demonstram a existência de efeitos sobre a divisão, alongamento e ultraestrutura celulares, crescimento induzido por hormônios, permeabilidade de membranas, absorção mineral, abertura estomática, fotossíntese, respiração, síntese protéica, metabolismo de lipídios e ácidos orgânicos, atividade de várias enzimas e nas relações hídricas do vegetal. (RICE, 1984).

Rice (1984) relata as interferências de plantas daninhas sobre a cultura da soja. Em estudos realizados com substrato de Abutilon theophrasti mostrou efeitos sobre as culturas do algodão e da soja sob diferentes densidades, localização e duração de interferência, levando a redução da produtividade nestas culturas. Também foram observados os efeitos dos resíduos de Cyperus esculentus sobre o crescimento de raízes e parte aérea de plantas de milho e soja. Ainda, a interferência de Setaria faberii e $S$. glauca levaram à diminuição da produtividade de culturas de milho, de soja e de sorgo (S. glauca), enquanto a interferência de Sorghum halepense causou danos sobre a produtividade de plantas de algodão, cana-de-açúcar, soja e milho.

As próprias plantas cultivadas podem exercer efeitos alelopáticos sobre outras culturas. Substâncias extraídas da palha de trigo e aveia, de caules de milho e sorgo, bem como de feno de soja, entre outras plantas, mostraram-se inibidores da germinação e do crescimento das raízes e parte aérea de plantas de trigo (GUENZI; McCALLA apud RICE, 1984). O sorgoleone, composto alelopático encontrado nos exsudados das raízes de sorgo, foi testado sobre plantas de feijão, trigo, caruru e soja, levando nesta última a fitotoxicidade crescente à medida que se aumentou a concentração do composto, a qual refletiuse na redução do porte da planta e um murchamento acentuado. (SOUZA; SOUZA; PASQUAL, 1999).

Em algumas regiões do Brasil é comum o cultivo de trigo e de outras culturas, nos meses de inverno, antecedendo as culturas de verão. Para verificar a possibilidade de efeitos alelopáticos das culturas de inverno sobre as que as seguem, Almeida e Rodrigues (1985 apud ALMEIDA, 1988), procederam a ensaios de germinação de feijão, milho e soja, usando extratos aquosos de palha de plantas adultas de trigo, aveia, centeio, tremoço e nabo forrageiro. A percentagem da germinação das espécies testadas foi pouco afetada, mas o comprimento da raiz e da parte aérea das plântulas reduziu-se.

A sucessão de algumas culturas como milho-trigo e trigo-trigo não é recomendada devido à redução 
de produtividade da segunda safra, provocada possivelmente pelos aleloquímicos liberados pela primeira cultura. Durante as primeiras semanas de decomposição dos resíduos de milho no solo, ainda verifica-se toxicidade, inibindo o crescimento de plântulas de trigo. Toxicidade também constatada durante a decomposição de resíduos de trigo no solo, reduzindo a produtividade da segunda safra de trigo. (GUENZI et al., 1967 ; KIMBER, 1973 apud ALMEIDA, 1988).

Trabalhos relacionados com a exsudação radicular também puderam constatar efeitos benéficos dos aleloquímicos, como foi o caso do tremoço-branco (Lupinus albus) e o milho (Zea mays) que exsudam aleloquímicos pelas raízes impedindo o crescimento da ançarinha-branca (Chenopodium albus) e caruru (Amaranthus retroflexus). (DZUBENKO; PETRENKO, 1971 apud ALMEIDA, 1988).

O objetivo deste trabalho foi estudar o efeito de substâncias naturais encontradas em exsudados radiculares de outras culturas, na geminação da soja, e verificar a influência de extratos de aveia preta (Avena strigosa), sobre a germinação de sementes de soja.

\section{Material e Métodos}

\section{Experimento I}

Para a germinação das sementes foram utilizados rolos de papel filtro (Germiteste), previamente autoclavados a mais de $100^{\circ} \mathrm{C}$, por aproximadamente $20 \mathrm{~min}$. Os rolos de papel foram acondicionados em sacos plásticos, e colocados na câmara de vegetação, $\mathrm{BOD}$, à temperatura de $25^{\circ} \mathrm{C}$, sob fotoperíodo de $12 \mathrm{hs}$ de escuro e $12 \mathrm{hs}$ de luz. A limpeza da BOD foi feita com o uso de uma solução Lysoform 10\%, (desinfetante), seguido pelo uso de Nistatina 10\%, (antifúngico). Esse mesmo tratamento foi utilizado para a limpeza da bancada onde as sementes foram contadas, com objetivo de diminuir ao máximo a contaminação.
Sementes de trigo (Triticum aestivum), triticale (Triticum sp.), aveia preta (Avena strigosa), milho (Zea mays) e ervilhaca (Vicia sativa), separadamente, foram inicialmente semeadas em rolos de papel filtro embebidos em água destilada, mantida as condições anteriormente descritas, por 10 dias, quando foram descartadas e o papel reutilizado para a germinação da soja por 7 dias, utilizando os exsudados liberados pelas sementes anteriormente dispostas sobre o papéis, como soluçãoteste. Como controle foi utilizado papel filtro embebido em água destilada.

Como tratamento fitossanitário prévio, as sementes das espécies que tiveram seus exsudados testados, passaram por desinfestação em hipoclorito de sódio $20 \%$, por $5 \mathrm{~min}$, enquanto as sementes de soja, uma bateria por $5 \mathrm{~min}$ e outra por $10 \mathrm{~min}$, para posterior analise de possíveis interferências quanto a esse parâmetro.

Tabela 1. Tratamentos utilizados para a germinação das sementes de soja, experimento I.

\begin{tabular}{lcc}
\hline Tratamento & $\begin{array}{c}\text { Tempo de imersão em } \\
\text { hipoclorito de sódio (min.) }\end{array}$ & Exsudados \\
\hline $\mathrm{T}_{1}$ & 5 & Água destilada \\
$\mathrm{T}_{2}$ & 10 & Água destilada \\
$\mathrm{T}_{3}$ & 5 & Ervilhaca \\
$\mathrm{T}_{4}$ & 10 & Ervilhaca \\
$\mathrm{T}_{5}$ & 5 & Trigo \\
$\mathrm{T}_{6}$ & 10 & Trigo \\
$\mathrm{T}_{7}$ & 5 & Triticale \\
$\mathrm{T}_{8}$ & 10 & Triticale \\
$\mathrm{T}_{9}$ & 5 & Aveia preta \\
$\mathrm{T}_{10}$ & 10 & Aveia Preta \\
$\mathrm{T}_{11}$ & 5 & Milho \\
$\mathrm{T}_{12}$ & 10 & Milho \\
\hline
\end{tabular}

\section{Experimento II}

Neste caso, utilizou-se extrato aquoso da parte área de aveia preta (Avena strigosa), como umidificante do papel, onde posteriormente as sementes de soja foram adicionadas para germinar. As porções aéreas de aveia preta, com aproximadamente 75 dias, foram trituradas com água destilada em liquidificador, resultando em uma solução 
de $20 \%$. Como controle foi utilizado papel filtro embebido em água destilada. $\mathrm{O}$ experimento foi acompanhado por 8 dias. Para a germinação das sementes foram também utilizados rolos de papel filtro (Germiteste), acondicionados em sacos plásticos, e colocados para germinar em BOD à temperatura de $25^{\circ} \mathrm{C}$, sob fotoperíodo de $12 \mathrm{hs}$ de escuro e $12 \mathrm{hs}$.

Como tratamento fitossanitário prévio, as sementes de soja passaram por tratamento de hipoclorito de sódio $20 \%$, por $5 \mathrm{~min}$ e por $10 \mathrm{~min}$.

Tabela 2. Tratamentos utilizados para a germinação das sementes de soja, experimento II.

\begin{tabular}{lcc}
\hline Tratamento & $\begin{array}{c}\text { Tempo de imersão em } \\
\text { hipoclorito de sódio (min.) }\end{array}$ & Extratos \\
\hline $\mathrm{T}_{1}$ & 5 & Água destilada \\
$\mathrm{T}_{2}$ & 10 & Água destilada \\
$\mathrm{T}_{3}$ & 5 & Aveia preta \\
$\mathrm{T}_{4}$ & 10 & Aveia preta \\
\hline
\end{tabular}

\section{Avaliação dos experimentos}

Para ambos experimentos, a avaliação foi através da contagem diária das sementes germinadas, e foram consideradas germinadas as que apresentaram raiz igual ou maior de $2 \mathrm{~mm}$. O delineamento experimental foi inteiramente casualizado, com 4 repetições, sendo cada uma destas com 50 sementes para os 12 tratamentos, no primeiro experimento, e para os 4 tratamentos no segundo.

Os dados obtidos para porcentagem de germinação foram submetidos à análise de variância (teste F), utilizando-se a transformação arco seno da raiz quadrada da porcentagem, sendo as médias comparadas pelo teste de Tukey a $1 \%$ de probabilidade. (PIMENTEL-GOMES, 1990). Além disso, foram realizadas observações quanto ao tempo médio de germinação $(\mathrm{t})$ e à velocidade média de germinação (v), calculados segundo Labouriau (1983). Para encontrar o tempo médio de germinação utiliza-se a somatória da multiplicação do número de sementes germinadas no intervalo de tempo pelo tempo, dividido pelo numero total de sementes germinadas. Para a velocidade média divide-se 1 pelo tempo médio de germinação.

\section{Resultados e Discussão}

Experimento I - Efeitos de exsudados radiculares sobre germinação de sementes de soja

Analisando a tabela 3, pode - se notar que, em geral, todos os tratamentos resultaram em uma alta porcentagem de germinação, variando de 88,5 a 98,5 $\%$, onde a menor porcentagem de germinação foi registrada para as sementes de soja, tratadas com exudados radiculares de triticale, mantidas por $5 \mathrm{~min}$ no hipoclorito. A maior porcentagem de germinação foi para as sementes tratadas com exudados radiculares de milho.

O efeito do tempo de imersão das sementes de soja no hipoclorito de sódio não apresentou diferença estatística para a porcentagem de germinação das sementes. Analisando numericamente, a porcentagem de germinação decaiu para a maioria das sementes que permaneceram por 10 minutos no tratamento fitossanitário, mas com baixa significância.

Exudados radiculares de milho, apresentaram neste caso, o melhor efeito para a germinação das sementes de soja, mas com pequena diferença da porcentagem de germinação da testemunha. Um resultado pouco relevante quando no campo.

Em alguns experimentos já realizados, como o de Guenzi et al. (1967); Kimber (1973) citados por Almeida (1988), conclui-se que na sucessão da cultura de milho-trigo, ocorre inibição do crescimento de plântulas de trigo. Neste caso nota-se uma influência negativa do milho sobre outra cultura, divergindo da conclusão do presente trabalho, onde as sementes de soja germinaram em maior numero quando tratadas com exsudados de milho. Mas devese lembrar que os efeitos alelopáticos no campo podem diferir dos efeitos encontrados em experimentos em laboratório. Mesmo porque, como relatado por Einhellig (1985 apud ALMEIDA, 1988), a interferência com microrganismos do solo e as 
diferentes composições deste, podem gerar variações nos resultados.

Os autores Dzubenko e Petrenko (1971 apud ALMEIDA, 1988), trabalhando com exsudados radiculares de milho (Zea mays), puderam constatar que aleloquímicos exsudados impediam o crescimento de plantas daninhas como o caruru (Amaranthus retroflexus), demonstrando assim o efeito alelopático desse tratamento.

Quanto à análise da velocidade e tempo médio de germinação das sementes de soja, não houve diferença significativa nos resultados obtidos.

Tabela 3. Porcentagem, tempo médio e velocidade de germinação de sementes de soja (Glycine max L. Merrill) submetidas a diferentes tratamentos.

\begin{tabular}{cccc}
\hline Tratamentos & Porcentagem & $\begin{array}{c}\text { Tempo médio } \\
\text { (dias) }\end{array}$ & $\begin{array}{c}\text { Velocidade } \\
\text { (sementes/dias) }\end{array}$ \\
\hline $\mathrm{T}_{1}$ & $95,5 \mathrm{ab}$ & $2,082 \mathrm{a}$ & $1,926 \mathrm{a}$ \\
$\mathrm{T}_{2}$ & $95,0 \mathrm{ab}$ & $2,015 \mathrm{a}$ & $1,986 \mathrm{a}$ \\
$\mathrm{T}_{3}$ & $94,5 \mathrm{ab}$ & $2,042 \mathrm{a}$ & $1,961 \mathrm{a}$ \\
$\mathrm{T}_{4}$ & $91,0 \mathrm{~b}$ & $2,060 \mathrm{a}$ & $1,946 \mathrm{a}$ \\
$\mathrm{T}_{5}$ & $93,0 \mathrm{ab}$ & $2,130 \mathrm{a}$ & $1,881 \mathrm{a}$ \\
$\mathrm{T}_{6}$ & $90,5 \mathrm{~b}$ & $2,085 \mathrm{a}$ & $1,922 \mathrm{a}$ \\
$\mathrm{T}_{7}$ & $88,5 \mathrm{~b}$ & $2,137 \mathrm{a}$ & $1,872 \mathrm{a}$ \\
$\mathrm{T}_{8}$ & $92,0 \mathrm{ab}$ & $2,087 \mathrm{a}$ & $1,919 \mathrm{a}$ \\
$\mathrm{T}_{9}$ & $94,5 \mathrm{ab}$ & $2,092 \mathrm{a}$ & $1,935 \mathrm{a}$ \\
$\mathrm{T}_{10}$ & $91,0 \mathrm{~b}$ & $2,074 \mathrm{a}$ & $1,929 \mathrm{a}$ \\
$\mathrm{T}_{11}$ & $98,5 \mathrm{a}$ & $2,052 \mathrm{a}$ & $1,950 \mathrm{a}$ \\
$\mathrm{T}_{12}$ & $96,5 \mathrm{ab}$ & $2,031 \mathrm{a}$ & $1,972 \mathrm{a}$ \\
\hline $\mathrm{CV}$ & 6,17 & 4,89 & 4,74
\end{tabular}

Médias seguidas de mesma letra na coluna, não diferem significativamente entre si, no nível de $1 \%$ de probabilidade.

Experimento II-Efeito de extrato aquoso de aveia preta sobre a germinação de sementes de soja

Através da análise dos dados da tabela 4, resultado do experimento com sementes de soja, tratadas com extratos de aveia preta, foi possível observar que não houve diferença significativa, em relação à porcentagem de sementes germinadas para os diferentes tratamentos realizados. Essa porcentagem manteve-se entre 91 a $88 \%$.

Houve influência sobre o tempo médio de germinação, visto que as sementes de soja com o tratamento testemunha, germinaram em menor tempo do que as tratadas com extrato de aveia. Conseqüentemente para o parâmetro velocidade de germinação também se notou uma diferença significativa entre os tratamentos, tendo as sementes tratadas com extrato de aveia uma velocidade menor de germinação que as sementes tratadas apenas com água.

Almeida e Rodrigues (1985 apud ALMEIDA, 1988), realizaram ensaios com germinação de soja, além de outras culturas, usando extrato aquosos de plantas adultas de trigo, centeio, tremoço, nabo forrageiro e aveia, e não obtiveram interferência na porcentagem de germinação das espécies testadas, mas observaram redução no comprimento da raiz e da parte aérea das plântulas, devido ao efeito alelopático da aveia. Esses resultados foram comprovados com experimentos em condições de campo.

Efeitos alelopáticos da aveia também foram constatados sobre plantas daninhas, como o capimmarmelada (Brachiaria plantaginea), entre outras. (ALMEIDA; RODRIGUES, 1985 apud ALMEIDA, 1988).

Tabela 4. Porcentagem, tempo médio e velocidade de germinação de sementes de soja (Glycine max L. Merrill) submetidas ao tratamento de extrato de aveia preta (Avena strigosa).

\begin{tabular}{cccc}
\hline Tratamentos & Porcentagem & $\begin{array}{c}\text { Tempo médio } \\
\text { (dias) }\end{array}$ & $\begin{array}{c}\text { Velocidade } \\
\text { (sementes/dias) }\end{array}$ \\
\hline $\mathrm{T}_{1}$ & $89,5 \mathrm{a}$ & $2,122 \mathrm{~b}$ & $1,888 \mathrm{a}$ \\
$\mathrm{T}_{2}$ & $91,0 \mathrm{a}$ & $2,093 \mathrm{~b}$ & $1,920 \mathrm{a}$ \\
$\mathrm{T}_{3}$ & $88,5 \mathrm{a}$ & $3,296 \mathrm{a}$ & $1,219 \mathrm{~b}$ \\
$\mathrm{~T}_{4}$ & $88,0 \mathrm{a}$ & $3,192 \mathrm{a}$ & $1,254 \mathrm{~b}$ \\
\hline $\mathrm{CV}$ & 9,02 & 6,70 & 6,82 \\
\hline
\end{tabular}

Médias seguidas de mesma letra na coluna, não diferem significativamente entre si, no nível de $1 \%$ de probabilidade. 


\section{Conclusão}

Nas condições em que se desenvolveu este trabalho, constatou-se interferência dos exsudados radiculares dos diferentes tratamentos testados, sobre a porcentagem de germinação das sementes de soja. Efeitos alelopáticos não foram verificados sobre o tempo e velocidade média de germinação das sementes de soja.

Pôde-se notar interferência negativa do extrato de aveia preta, sobre o tempo e velocidade média de germinação de sementes de soja.

\section{Referências}

ALMEIDA, F.S. Alelopatia e as pantas. Londrina: IAPAR, 1988.

COSTA, J.A. Cultura da soja. Porto Alegre: inco Continentes, 1996.

LABOURIAU, L.G. A germinação de sementes. Washington: Organização dos Estados Americanos, 1983.

PIMENTEL-GOMES, F. Curso de estatística experimental. São Paulo, 1990.

RAVEN, P.H; EVERT, R.F.; EICHHORN, S.E. Biologia vegetal. 6.ed. Rio de Janeiro: Guanabara Koogan S.A, 2001.

RICE, E.L. Allelophaty. Orlando: Academic Press, 1984.

SOUZA, C.N.; SOUZA, I.T.; PASQUAL, M. Extração e ação de sorgoleone sobre o crescimento de plantas. Ciência e Agrotecnologia, Lavras, v.23, n.2, p.331-338, 1999.

TAIZ, L.; ZEIGER, E. Plant defenses; surface protection and secondary metabolites. In: Sunderland: Sinauer, 1998. p.347-375. 